\title{
PROFESSORES DA EDUCAÇÃO BÁSICA: PERFIL E PERCEPÇÕES SOBRE SUCESSO DOS ALUNOS
}

ELOISA MAIA VIDAL SOFIA LERCHE VIEIRA

\section{RESUMO}

O trabalho aprofunda interfaces entre formação docente, avaliações de larga escala e politicas educacionais. Analisa estudos sobre características docentes associadas à melhoria do desempenho de estudantes em tais avaliações, cotejando-as com dados de professores brasileiros obtidos no Questionário do Professor da Prova Brasil/ Avaliação Nacional da Educação Básica 2013. A amostra, submetida à análise estatística descritiva, é formada por 107.278 docentes do $5^{\circ}$ ano e 118.772 do $9^{\circ}$ ano. Os resultados evidenciam alguns elementos do perfil docente, tais como sexo, idade, tempo de exercício profissional, raça e formação. Dentre os problemas identificados, está o descompasso entre a formação e as orientações legais vigentes. Outra questão a considerar refere-se às percepções docentes de que os fatores externos à escola são mais relevantes que os fatores internos nas deficiências de aprendizagem. Reverter tais expectativas é questão a ser considerada na formulação de políticas de formação docente.

PALAVRAs-CHAVE FoRMAÇÃo DOCENTE - PROVA BRASIL • SUCESSO ESCOLAR • PERCEPÇÃO DOCENTE. 


\section{PROFESORES DE EDUCACIÓN BÁSICA: PERFIL Y PERCEPCIONES SOBRE EL ÉXITO DE LOS ALUMNOS \\ RESUMEN}

El trabajo profundiza las interfaces entre formación docente, evaluaciones de amplia escala y políticas educacionales. Analiza estudios sobre características docentes asociadas a la mejora en desempeño de los alumnos, comparándolas con datos de profesores brasileños del Cuestionario del Profesor de la Prueba Brasil/ Evaluación Nacional de la Educación Básica 2013. La muestra, sometida al análisis estadístico descriptivo, tiene 107.278 docentes del $5^{\circ}$ año y 118.772 del $9^{\circ}$ año. Los resultados señalan elementos del perfil docente, como sexo, edad, tiempo del ejercicio profesional, raza y formación. Es posible notar incompatibilidad entre la formación y las orientaciones legales vigentes. Los docentes perciben los factores externos a la escuela como más relevantes en el aprendizaje que los factores internos. Hay que considerar la reversión de tales expectativas en la formulación de políticas de formación docente.

PALABRAS CLAVE FORMACIÓN DOCENTE • PRUEBA BRASIL • ÉXITO ESCOLAR • PERCEPCIÓN DOCENTE.

\section{TEACHERS OF BASIC EDUCATION: PROFILE AND PERCEPTIONS ABOUT STUDENT SUCCESS \\ ABSTRACT}

This paper discusses interfaces between teacher training and educational policies. It analyses studies about teacher characteristics associated with improvements in student performance, by matching them with data of Brazilian teachers obtained from the Questionário do Professor da Prova Brasil/Avaliação Nacional da Educação Básica 2013 [Teacher of the Prova Brasil Test/National Assessment of Basic Education]. The sample is composed of 107,278 fifth grade teachers and 118,772 ninth grade teachers. The results show aspects of the teaching profile, including sex, age, professional practice, race and training. Some important gaps deserve attention, such as the training non-compliant with current legal guidelines. Faculty perceptions about student learning problems point to factors external to school, as more relevant to learning than internal factors. Reversing such expectations is a matter to be considered in the development of training policies.

KEYWORDS TEACHER TRAINING - PROVA BRASIL • SCHOOL SUCCESS • TEACHER PERCEPTION. 


\section{INTRODUÇÃO}

A formação de professores constitui tema amplamente discutido na política educacional brasileira, de modo especial nas últimas décadas, quando o Brasil começou a participar de avaliações internacionais, a exemplo do Programme for International Student Assessment (Pisa), do Laboratório Latinoamericano de Evaluación de la Calidad de la Educación (Llece), e criou o Índice de Desenvolvimento da Educação Básica (Ideb). Embora o Ideb procure mensurar variáveis relacionadas ao fluxo escolar e ao desempenho dos alunos nas disciplinas de Língua Portuguesa e Matemática nos $5^{\circ}$ e $9^{\circ}$ anos do ensino fundamental e $3^{\circ}$ ano do ensino médio e, portanto, se refira à avaliação de alunos, é preciso reconhecer o protagonismo docente nos resultados de aprendizagem, conforme apontam estudos internacionais.

Este artigo procura mapear indicações da literatura internacional e nacional acerca de atributos e/ou características dos docentes que estão direta ou indiretamente associados com melhoria nos resultados de desempenho dos alunos, observados nas avaliações de larga escala, e cotejá-las com dados 
obtidos sobre os professores brasileiros no Questionário do Professor aplicado junto com a Prova Brasil/Avaliação Nacional da Educação Básica (Aneb) no ano de 2013 (BRASIL, 2013). O interesse surgiu em decorrência dos resultados de desempenho dos alunos brasileiros nas avaliações de larga escala, que, apesar de apresentarem pequenas melhorias nos últimos anos, ainda se situam em patamares expressivamente inferiores aos desejados, como mostram os resultados do Pisa 2012, Sistema de Avaliação da Educação Básica (Saeb) 2013 e, mais recentemente, os dados do do Terceiro Estudo Regional Comparativo e Explicativo (Terce) 2013. ${ }^{1}$ O objetivo principal do trabalho é analisar algumas características dos docentes do ensino fundamental, obtidas a partir de dados da Prova Brasil/Aneb 2013, com vistas a identificar fatores explicativos desses resultados que possam vir a orientar políticas de formação desses profissionais.

\section{O PROTAGONISMO DOCENTE E AS AVALIAÇÕES DE LARGA}

\section{ESCALA}

As avaliações de larga escala aplicadas no âmbito nacional e internacional contribuíram para a emergência de estudos acerca do perfil dos professores que atuam nas escolas, procurando identificar atributos ou características desses profissionais que poderiam estar associados ao sucesso escolar dos alunos.

Dois estudos produzidos pela McKinsey \& Company, grupo internacional de consultoria não diretamente ligado ao campo educacional, e denominados, respectivamente, Como os sistemas escolares de melhor desempenho do mundo chegaram ao topo (2007) e Educação - como um sistema escolar de baixo desempenho pode evoluir para tornar-se bom? E como um sistema de bom desempenho pode atingir o nível de excelência? (2010), põem em relevo a importância dos docentes para a melhoria de desempenho dos alunos nos sistemas educativos. Um estudo realizado pela Unidade de Inteligência do The Economist em parceria com a Pearson, intitulado The learning curve -lessons in country performance in education (2012), também destaca o protagonismo docente.

O primeiro estudo da McKinsey \& Company (2007) analisa o desempenho de 25 sistemas educativos participantes
1 O Terce foi realizado pelo

Laboratório Latinoamericano de

Evaluación de la Calidad de la

Educación (Llece), aplicado em 2013

pela Organización de Las Naciones

Unidas para la Educación, la Ciencia y la Cultura (Unesco/Santiago) e do qual participaram os seguintes países: Argentina, Brasil, Chile, Colômbia, Costa Rica, Equador, Guatemala,

México, Nicarágua, Panamá, Paraguai, Peru, República Dominicana, Uruguai e o estado mexicano de Nuevo Leon (Disponível em: <http://portal.inep. gov.br/terce>. Acesso em: 2 fev. 2016) 
do Pisa, dentre os quais: os dez com melhor desempenho, aqueles com significativa trajetória de melhoria e os que estão implantando programas de melhoria. O objetivo foi identificar os aspectos em comum entre os sistemas com alto desempenho e as estratégias por eles utilizadas na melhoria de resultados de seus alunos. Constatou-se que o êxito desses sistemas educativos se devia a três aspectos: 1) recrutar pessoas mais aptas para o exercício da profissão de docente; 2) desenvolvê-las no sentido de convertê-las em professores eficientes; e 3) assegurar a oferta da melhor instrução possível a todas as crianças. O estudo mostra ainda que: a) não há uma relação direta e imediata entre gastos, reformas e resultados; b) exceto nos primeiros anos escolares, a redução do número de alunos não tem grande impacto na qualidade dos resultados; c) $o$ principal vetor de variação na aprendizagem escolar é a qualidade dos docentes; d) as mudanças e melhorias devem ocorrer em todas as partes do sistema; e) os sistemas com melhor desempenho adotaram estratégias e práticas de forma a atrair os melhores candidatos à carreira de docente, que consistem em desenvolver mecanismos eficientes para selecionar os professores que receberão capacitação e pagamento de bons salários iniciais; f) a única maneira de melhorar os resultados de desempenho dos alunos é melhorar a formação do professor; e g) garantir que cada aluno receba a instrução que necessita para compensar as deficiências de seu entorno.

O segundo estudo da McKinsey \& Company (2010) procura responder como um sistema escolar de baixo desempenho pode evoluir para tornar-se bom e como um sistema de alto desempenho pode atingir o nível de excelência. Para responder a essas indagações, foram analisados 20 sistemas nos vários continentes, que apresentavam níveis de desempenho crescente e que se situavam em diferentes pontos de partida, segundo dados de relatórios de avaliações nacionais e internacionais. O relatório destaca pontos passíveis de serem reproduzidos por sistemas educacionais que se propõem a sair da situação de desempenho fraco em busca de melhores posições na escala. Preocupados em melhorar o aprendizado dos alunos em sala de aula, tais sistemas adotam três medidas que implicam mudanças: a) na estrutura, 
criando novas instituições ou tipos de escolas, modificando os anos ou os níveis de escolaridade ou descentralizando as responsabilidades pelo sistema; b) nos recursos, alocando mais profissionais na escola ou incrementando o financiamento do sistema; e c) nos processos, alterando o currículo e melhorando a maneira como os professores ensinam e como os diretores lideram as equipes. Embora as duas primeiras medidas sejam mais visíveis, o aperfeiçoamento dos processos, procurando melhorar a formação dos professores e suas práticas em sala de aula, é o que provoca impactos mais significativos.

O propósito do terceiro estudo, realizado pela Unidade de Inteligência do The Economist, é identificar as iniciativas dos sistemas educacionais que conduzem a resultados de sucesso do ponto de vista econômico e social. Uma constatação do relatório é que bons professores exercem profunda influência sobre a vida escolar dos alunos, com repercussões ligadas não somente ao aumento de renda futura, mas também a uma série de resultados sociais, incluindo menor chance de gravidez na adolescência e uma maior tendência a poupar para a própria aposentadoria. No entanto, não é possível descrever de forma objetiva uma lista de traços para definir ou identificar um bom professor e muito menos há uma receita universal para chegar a eles. Nos sistemas educativos com melhores resultados de desempenho, observa-se que os professores recebem uma formação inicial de alta qualidade, sentem-se responsáveis por prestar contas à sociedade e imbuídos de uma missão moral subjacente aos esforços de educação.

Embora destaque que um sistema educacional ainda pode ser apontado como uma "caixa preta" na qual não se tem clareza sobre correlações entre entradas e saídas, o relatório chega a algumas constatações, como o fato de que sistemas de alto desempenho escolar combinam padrões exigentes, baixa tolerância a falhas e clara articulação das expectativas de aprendizagem com muita responsabilidade profissional por meio de uma organização do trabalho colaborativo entre professores e escolas.

Segundo os estudos aqui descritos, o principal fator responsável pela variação na aprendizagem escolar é a qualidade dos docentes. Essas conclusões são encontradas nos 
estudos da McKinsey \& Company (2007, 2010). Enquanto o primeiro estudo informa que os sistemas que apresentam melhores desempenhos atraem os melhores candidatos à carreira de docente e que a única maneira de aprimorar os resultados de desempenho dos alunos é investindo na formação do professor, o segundo revela que a melhoria contínua dos sistemas é mantida por um equilíbrio entre a autonomia das escolas e a uniformidade das práticas de ensino. $\mathrm{O}$ relatório do The Economist reconhece a influência que o professor exerce na trajetória escolar do aluno, ultrapassando inclusive os aspectos educacionais e se estendendo por outras dimensões da vida adulta. Importante destacar que, embora esses estudos procurem equalizar algumas variáveis para análise de outras, minimizam os efeitos dos contextos sociais e culturais das sociedades, que, no caso da atuação docente, possuem grande relevância.

No Brasil, a importância dos docentes na melhoria do desempenho dos estudantes emerge como decorrência de pesquisas acerca dos fatores associados ao sucesso escolar e começam a surgir no início dos anos 1990. Com a criação do Ideb, em 2007, quando passa a ser possível estabelecer algum tipo de comparação entre o desempenho de estados, municípios e escolas, novos estudos são produzidos, razão pela qual três deles serão aqui sintetizados.

O primeiro desses estudos foi o Aprova Brasil - o direito de aprender: boas práticas em escolas públicas avaliadas para Prova Brasil, produzido pelo Instituto Nacional de Estudos e Pesquisas Educacionais Anísio Teixeira (Inep) em parceria com o Fundo das Nações Unidas para a Infância (Unicef) e publicado em 2007, a partir de dados obtidos na Prova Brasil 2005. Esse trabalho procura identificar iniciativas comuns às escolas que, apesar de um contexto socioeconômico desfavorável, tiveram êxito em assegurar o direito de cada criança aprender. A amostra consistiu de 33 escolas públicas urbanas com notas acima da média na avaliação de desempenho em Leitura e Matemática dos alunos de $4^{\mathrm{a}}$ e $8^{\mathrm{a}}$ séries do ensino fundamental.

A pesquisa mostrou que o desempenho dos estudantes se revelou fruto de um conjunto de fatores articulados entre 
si, não sendo possível atribuir contribuições isoladas e específicas de cada um deles. Mostrou também que é na confluência de vontade de e compromisso com - do poder público, dos gestores das escolas e dos variados parceiros - assegurar a educação de qualidade, como base para a garantia do direito de aprender, que esses resultados são planejados e alcançados.

Entre as constatações, podemos destacar: a) a centralidade do papel do professor, o que não significa atribuir a ele a responsabilidade isolada pela aprendizagem do aluno; b) a valorização e o respeito ao aluno, à sua cultura, ao que ele traz para a escola, ou seja, ver no aluno a solução, invertendo um enunciado, muitas vezes afirmado, de que o aluno é um problema; c) a importância de espaços e instrumentos de participação efetiva desse conjunto de atores e de seus parceiros, capazes de uma atuação transformadora inserida em um ambiente de gestão democrática da escola; d) as diversas práticas de estímulo ao processo cognitivo por meio de atividades lúdicas, metodologias inovadoras, espaços educativos e busca de novas abordagens; e) nenhuma prática isolada, por melhor que seja, é capaz de gerar condições efetivas de aprendizagem (BRASIL; FUNDO DAS NAÇÕES UNIDAS PARA A INFÂNCIA - UNICEF, 2007, p. 64).

Embora o estudo não tivesse por objetivo mapear as dificuldades enfrentadas pelas escolas em busca da melhoria de resultados de aprendizagem, foram constatados problemas: nas áreas de infraestrutura e falta de espaços e materiais; no isolamento das escolas mais distantes e mesmo entre escolas de uma mesma rede escolar; nas demandas produzidas pelas diferentes instâncias do poder público sobre a escola; na expectativa das famílias; e até mesmo no descrédito da comunidade.

Na sequência, é publicado o estudo Redes de Aprendizagem: boas práticas de municípios que garantem o direito de aprender (BRASIL; UNICEF; UNIÃO DOS DIRIGENTES MUNICIPAIS DE EDUCAÇÃO - UNDIME [ca. 2009]). Embora sem identificação de data na publicação, sua divulgação ocorre entre os anos 2008 e 2009, dando continuidade ao trabalho iniciado com a pesquisa anteriormente focalizada. $O$ alvo são os resultados de 37 redes municipais selecionadas a partir do Ideb 2005 e 
dos contextos socioeconômicos dos alunos e de sua família. A pergunta orientadora da pesquisa foi: "o que faz essa rede de ensino para garantir o direito de aprender das crianças?” As respostas obtidas se organizam em torno de dez fatores: a) aprendizagem - o foco que alinha toda a rede; b) gestão com consciência e práticas de rede; c) planejamento solidário; d) avaliação - ferramenta de aprendizagem; e) o valor do professor; f) compromisso com a formação; g) a valorização da leitura; h) um a um, nenhum a menos; i) atividades complementares fazem a diferença; j) parceiros da aprendizagem. Além desses dez fatores, a pesquisa também identificou aspectos que merecem destaque, como: a) acesso à educação infantil; b) interação com as famílias e a comunidade; c) prática por projetos; d) respeito ao tempo escolar; e) infraestrutura; f) perfil e papel da direção escolar; e g) plano de carreira, cargos e salários.

O terceiro estudo, Desempenho dos alunos na Prova Brasil: diversos caminhos para o sucesso educacional nas redes municipais de ensino (PARANDEKAR; OLIVEIRA; AMORIM, 2008), realizado no ano de 2007, focaliza a administração municipal e utiliza uma metodologia qualiquantitativa. Para identificar as redes a serem pesquisadas, do ponto de vista quantitativo, utilizou a base de dados da Prova Brasil 2005 e outras bases referentes à dimensão socioeconômica dos municípios, e realizou uma pesquisa de campo de natureza qualitativa, entrevistando os responsáveis pelas redes escolares. Depois de aplicados critérios de escolha e regressões estatísticas, chegou-se a 49 municípios. A questão motivadora da pesquisa foi a busca de "boas práticas de gestão que contribuíram para o bom desempenho dos alunos em determinadas redes municipais" (PARANDEKAR; OLIVEIRA; AMORIM, 2008, p. 25), tendo o foco da pesquisa se concentrado nas secretarias municipais de educação (SME). Foi identificado um conjunto de fatores associados ao bom desempenho das redes municipais, com destaque para: a) liderança do(a) secretário(a) municipal de educação; b) visão e planejamento; c) programas federais, estaduais e municipais destinados à educação; d) importância da educação infantil; e) caracterização da secretaria municipal de educação; f) apoio e acompanhamento das escolas; g) gestão escolar; h) professores atuantes, capacitados e compromissados 
com uma educação de qualidade; i) elos entre comunidade, secretarias municipais e escolas.

No caso dos estudos nacionais, a importância do professor no processo educativo também é destacada por meio de alguns atributos, como compromisso com a formação do aluno, utilização de metodologias inovadoras, capacidade de desenvolver processos cognitivos junto aos alunos, etc. Diferentemente dos estudos internacionais, que procuram apontar características específicas para os docentes desde a formação inicial, nos estudos brasileiros, esses atributos são citados de forma mais indireta ou mesmo relegados, como é o caso do recrutamento docente e da seleção.

Os estudos e pesquisas internacionais e nacionais demonstram que o esforço para a melhoria dos sistemas educacionais pode ser organizado num conjunto de iniciativas nas quais se destaca, de forma recorrente, o protagonismo docente. Os estudos nacionais apontam as mesmas tendências dos estudos internacionais no que se refere ao papel central do professor no processo de melhoria de um sistema educacional quanto ao desempenho escolar dos alunos. Vale observar que as pesquisas brasileiras tendem a apontar atributos de natureza mais subjetiva, como compromisso, atuação e envolvimento para a definição do bom professor.

A partir das referências apontadas nos estudos internacionais e nacionais, este trabalho procura investigar aspectos relacionados ao perfil dos professores que atuam nas séries avaliadas pela Prova Brasil/Aneb 2013, bem como algumas percepções desses docentes acerca das dificuldades de aprendizagem dos alunos. A hipótese orientadora da investigação é que, independentemente da adequação do perfil docente, suas percepções a respeito das capacidades e dificuldades de aprendizagem dos alunos têm forte impacto sobre a relação ensino aprendizagem.

\section{METODOLOGIA E BASE DE DADOS DO ESTUDO}

A Prova Brasil, formalmente denominada Avaliação Nacional do Rendimento Escolar (Anresc), é um dos componentes do Saeb. Ela é aplicada em todas as escolas públicas com 
pelo menos 20 estudantes matriculados nos $5^{\circ}$ e $9^{\circ}$ anos $\left(4^{\mathrm{a}}\right.$ e $8^{\text {a }}$ séries) do ensino fundamental regular, localizadas nas zonas urbanas e rurais. Já a Aneb procura manter os objetivos, características e procedimentos das avaliações anteriormente realizadas pelo Saeb, e é aplicada em uma amostra da população escolar, garantindo a continuidade da série histórica dos dados de proficiência dos alunos das redes públicas e privadas brasileiras.

Além das avaliações de Língua Portuguesa e Matemática realizadas com os estudantes, a Prova Brasil/Aneb aplica também questionários a alunos, professores, diretores e aplicadores das avaliações. Os chamados questionários contextuais direcionados aos professores de escolas públicas constituem fonte importante para a análise do perfil desses profissionais. Esses são constituídos de um conjunto de perguntas que, embora variem de um exame para outro, mantêm um núcleo comum e procuram investigar aspectos relacionados a: perfil dos docentes (formação, experiência profissional e características funcionais); desenvolvimento pessoal; hábitos de leitura/culturais; utilização de recursos audiovisuais e didáticos; integração da equipe escolar; problemas de aprendizagem; violência na escola; práticas pedagógicas e outras variáveis (Prova Brasil 2013).

Em 2013, o Questionário do Professor da Prova Brasil/ Aneb foi aplicado junto a 237.186 docentes, sendo 109.658 do $5^{\circ}$ ano, 121.310 do $9^{\circ}$ ano, 5.306 do $3^{\circ}$ ano do ensino médio e 912 do $3^{\circ}$ ano do ensino médio integrado. Esses professores estavam distribuídos em 56.737 escolas, sendo 183 federais, 20.176 estaduais, 34.387 municipais e 1.991 privadas. Dados obtidos na Sinopse Estatística da Educação Básica 2014 (BRASIL, 2016) informam que o Brasil possui 188.673 escolas de educação básica, sendo 543 federais, 30.758 estaduais, 117.797 municipais e 39.575 privadas. As matrículas, por sua vez, distribuem-se da seguinte forma: 296.745 na rede federal, 17.294.357 nas escolas estaduais, 23.089.488 nas redes municipais e 9.090 .781 em escolas privadas. Os gráficos 1a e $1 \mathrm{~b}$ permitem visualizar como se distribuem as matrículas e os estabelecimentos de ensino, por suas respectivas dependências administrativas. 
GRÁFICO 1A - Percentual de estabelecimentos de ensino de educação básica por dependência administrativa. Brasil, 2014

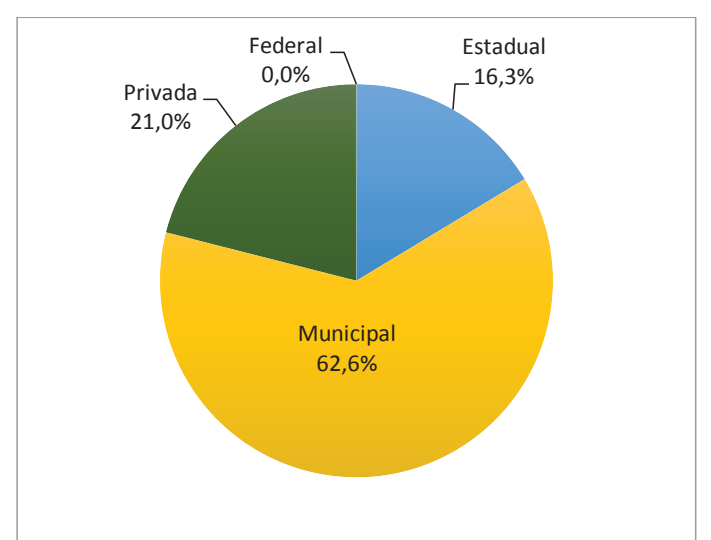

Fonte: Inep Prova Brasil/Aneb, 2013

Os dados permitem constatar que as redes municipais detêm $63 \%$ das escolas e $46 \%$ das matrículas de educação básica, atendendo os níveis de educação infantil, ensino fundamental e outras modalidades de oferta; a rede estadual possui $16 \%$ do total de estabelecimentos escolares e detém $35 \%$ das matrículas, com atendimento ao ensino fundamental, ensino médio, educação profissional e outras modalidades de oferta. Por outro lado, se observarmos a situação do atendimento ao ensino fundamental público, cujos professores são objeto de análise deste artigo, constataremos que, em 2014, segundo o Censo Escolar, 66,5\% das matrículas brasileiras ocorrem nas redes municipais, ${ }^{2}$ sendo que, no Ceará, esse valor chega a $95,0 \%$ e, no Amapá, a 37,5\%, ficando os demais estados com valores compreendidos nesse intervalo.

Quando se procura analisar a distribuição de matrículas públicas por etapa do ensino fundamental, constata-se que as redes municipais respondem por $82,1 \%$ das matrículas dos anos iniciais e por $47,8 \%$ das matrículas dos anos finais, o que aponta o predomínio da municipalização das séries iniciais e um compartilhamento de oferta das séries finais. Essa organização das etapas apresenta situações muito diversas entre as redes municipais: enquanto o Paraná detém 99,5\% das matrículas dos anos iniciais, os municípios do Acre ofertam $55,0 \%$ dessa etapa de escolaridade. Por outro lado, a
2 ○ Distrito Federal não possui rede municipal, sendo toda a matrícula registrada como estadual. 
situação dos anos finais revela que o Maranhão possui 91,3\% das matrículas municipalizadas e o Paraná, apenas 2,5\%.

A autonomia federativa e os arranjos político-administrativos locais contribuem para definir o modelo a ser implementado, como bem aponta Arretche (2006, p. 46) ao afirmar que, embora o governo federal tenda a assumir a coordenação das políticas sociais, "estados e municípios, por sua vez, contam com recursos garantidos, independentemente tanto da lealdade política ou adesão a políticas federais quanto de seu esforço tributário", o que faz com que as decisões do governo federal sejam limitadas. O caso do compartilhamento de oferta do ensino fundamental, como preconiza a legislação sobre o assunto e conforme os dados apresentados, revela a complexidade da situação no âmbito dos 27 estados (incluindo o Distrito Federal) e dos 5.561 munícipios.

Este artigo aprofunda alguns aspectos relacionados ao perfil dos docentes das redes públicas que atuam no ensino fundamental, nas disciplinas Língua Portuguesa e Matemática, e que responderam ao Questionário do Professor na Prova Brasil/Aneb 2013. Para fins de análise, foram excluídas dessa base de dados informações sobre docentes das escolas privadas e do ensino médio. Isso permitiu construir uma nova base de dados, com 226.050 professores que atuam no ensino fundamental, distribuídos em dois grandes grupos 107.278 docentes do $5^{\circ}$ ano e 118.772 do $9^{\circ}$ ano -, que foi submetida a análise, com uso de estatística descritiva. Para melhor situar os sujeitos da pesquisa, procurou-se identificar as escolas por dependência administrativa e localização geográfica, como mostram os gráficos 2a a 2d. 
GRÁFICO 2A - Percentual de professores do $5^{\circ}$ ano que responderam ao questionário da

GRÁFICO 2B - Percentual de professores do Prova Brasil/Aneb 2013, por dependência administrativa

$9^{\circ}$ ano que responderam ao questionário da
Prova Brasil/Aneb 2013, por dependência administrativa
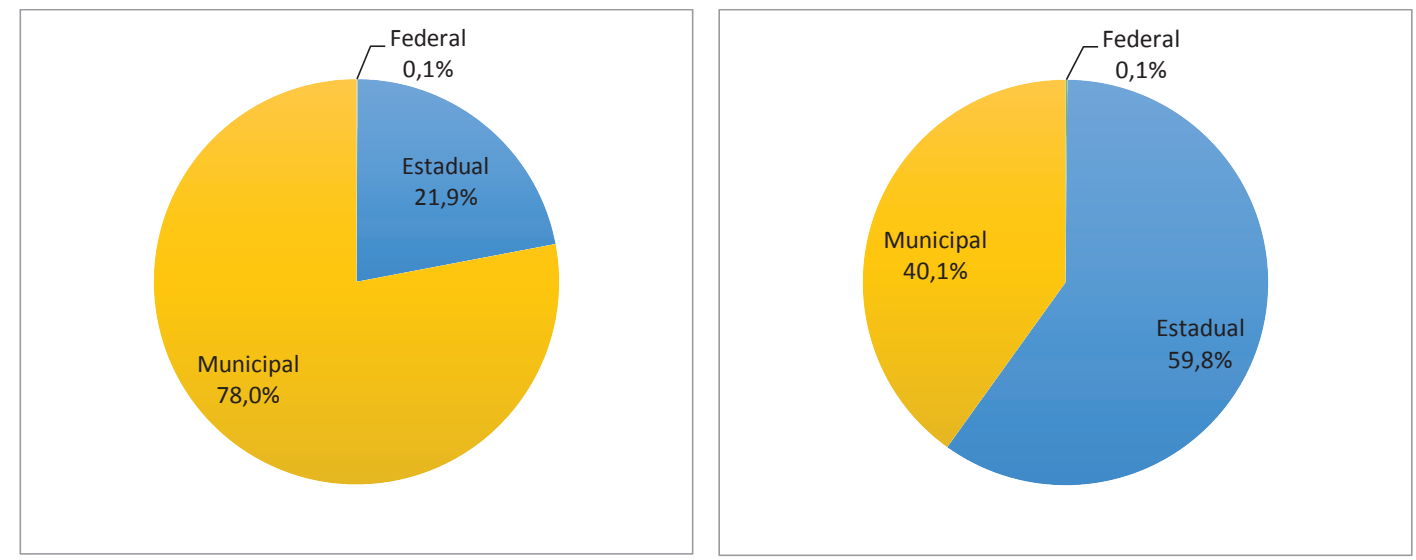

GRÁFICO 2C - Percentual de professores do $5^{\circ}$ ano que responderam ao questionário da Prova Brasil/Aneb 2013, por localização geográfica

GRÁFICO 2D - Percentual de professores do $9^{\circ}$ que responderam ao questionário da Prova

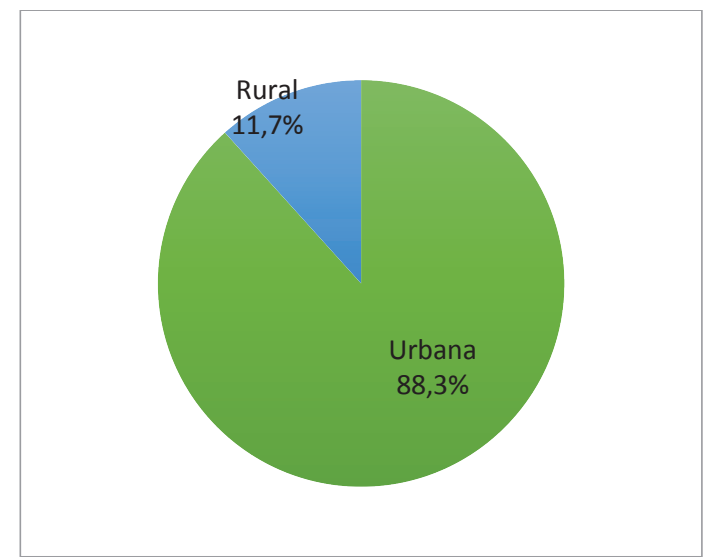
Brasil/Aneb 2013, por localização geográfica

Fonte: Elaboração das autoras a partir de dados do Inep, Prova Brasil, 2013.

Os dados apresentados nos gráficos 2a e 2b mostram que $78,0 \%$ dos professores do $5^{\circ}$ ano pertencem às redes municipais e $21,9 \%$, às redes estaduais; no $9^{\circ}$ ano, os docentes das redes estaduais respondem por $59,8 \%$ do total, enquanto 40,1\% são das redes municipais. Esses dados evidenciam a municipalização das séries iniciais do ensino fundamental, enquanto, nas séries finais, predomina a oferta compartilhada com as redes estaduais, como mostra a distribuição de 
matrículas do Censo Escolar 2014 para o universo de escolas públicas de educação básica. Os gráficos 2 c e 2 d evidenciam que tanto os professores do $5^{\circ}$ ano quanto os do $9^{\circ}$ ano atuam predominantemente em escolas urbanas.

\section{ELEMENTOS DO PERFIL DOCENTE}

Os dados apresentados no Gráfico 3 mostram como se distribuem os professores por sexo.

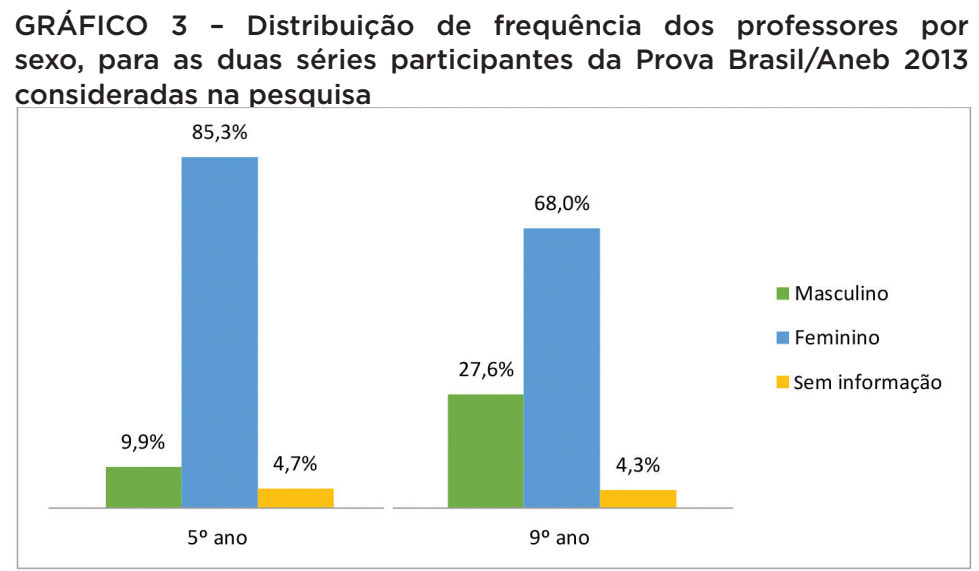

Fonte: Elaboração das autoras a partir de dados do Inep, Prova Brasil, 2013.

Quando estratificados por ano de aplicação do exame, observa-se que no $5^{\circ}$ ano temos $85,3 \%$ dos docentes do sexo feminino e no $9^{\circ}$ ano, $68,0 \%$. A feminização da profissão no ensino fundamental é tema amplamente discutido na literatura nacional e internacional (VAILLANT, 2006; BRASIl, 2014; WERLE, 2005) e se contrapõe à distribuição de gênero em outras profissões em que prevalece o sexo masculino ou uma distribuição mais equitativa. Na visão de Werle (2005, p. 610), esse processo no Brasil estaria relacionado ao "desprestígio do magistério, à sua baixa remuneração e qualificação, e ao fato de acolher moças originárias de camadas pobres da população".

Os dados da Tabela 1 apresentam informações sobre a idade dos docentes, observando a estratificação por ano de aplicação do exame. 
TABELA 1 - Distribuição dos professores por faixa etária, para as duas séries participantes da Prova Brasil/Aneb 2013 consideradas na pesquisa

\begin{tabular}{c|c|c}
\hline FAIXA ETÁRIA & $\mathbf{5}^{\circ}$ ANO & $\mathbf{9}^{\circ}$ ANO \\
\hline Até 24 anos & 2.689 & 4.467 \\
\hline De 25 a 29 anos & 8.567 & 12.415 \\
\hline De 30 a 39 anos & 34.372 & 39.279 \\
\hline De 40 a 49 anos & 38.882 & 37.695 \\
\hline De 50 a 54 anos & 10.762 & 11.843 \\
\hline 55 anos ou mais & 6.371 & 7.449 \\
\hline sem informação & 5.635 & 5.624 \\
\hline Total & $\mathbf{1 0 7 . 2 7 8}$ & $\mathbf{1 1 8 . 7 7 2}$ \\
\hline
\end{tabular}

Fonte: Inep, Prova Brasil/Aneb, 2013.

No $5^{\circ}$ ano, as faixas etárias predominantes são as de 30 a 39 anos (32,0\%) e de 40 a 49 anos (36,2\%), que juntas totalizam $68,2 \%$ dos docentes. Com menos de 29 anos de idade, são 10,5\% dos docentes, e com mais de 50 anos, $16,0 \%$. No $9^{\circ}$ ano, $33,1 \%$ dos docentes encontram-se na faixa de 30 a 39 anos, e $31,7 \%$, na faixa seguinte, de 40 a 49 anos, totalizando $64,8 \%$ dos professores na faixa de 30 a 49 anos. Com menos de 29 anos de idade, são $14,2 \%$ dos docentes e com mais de 50 anos, $16,2 \%$. A idade média dos docentes é 40 anos, o que leva a supor que o país apresenta um contingente expressivo de professores que já cumpriram mais de 15 anos de carreira profissional, aproximando-se da média de idade e tempo de exercício profissional dos países da Organização para a Cooperação e Desenvolvimento Econômico (OCDE), que é de 16 anos (VAILLANT, 2006).

O Gráfico 4 apresenta dados dos professores por cor/raça e pode-se constatar que, no $5^{\circ}$ ano, $42,0 \%$ identificam-se como brancos, valor que cresce para $49,6 \%$ no $9^{\circ}$ ano, enquanto $39,2 \%$ se reconhecem como pardos no $5^{\circ}$ ano e $33,9 \%$ no $9^{\circ}$ ano. No $5^{\circ}$ ano, $8,9 \%$ se declaram pretos e, no $9^{\circ}$ ano, $7,7 \%$. Dados do Instituto Brasileiro de Geografia e Estatística (IBGE) de 2011 mostram que a população residente no país se identifica como branca $(47,8 \%)$, parda $(43,1 \%)$ e preta $(8,2 \%),{ }^{3}$ podendo-se observar divergências maiores entre os dados de população e os professores que se declaram pardos nos dois anos do ensino fundamental. O fato da indagação sobre cor/raça ter cará-

3 Disponivel em: <http:// seriesestatisticas.jbge govbr/series. aspx?no=10\&op=0\&vcodigo =PD336 \&t=populacao-residente-cor-raca>. Acesso em: 2 maio 2016. ter declaratório pode estar associado a tais distorções. 
GRÁFICO 4 - Distribuição de frequência dos professores por cor/raça, para as duas séries participantes da Prova Brasil/Aneb 2013 consideradas na pesquisa

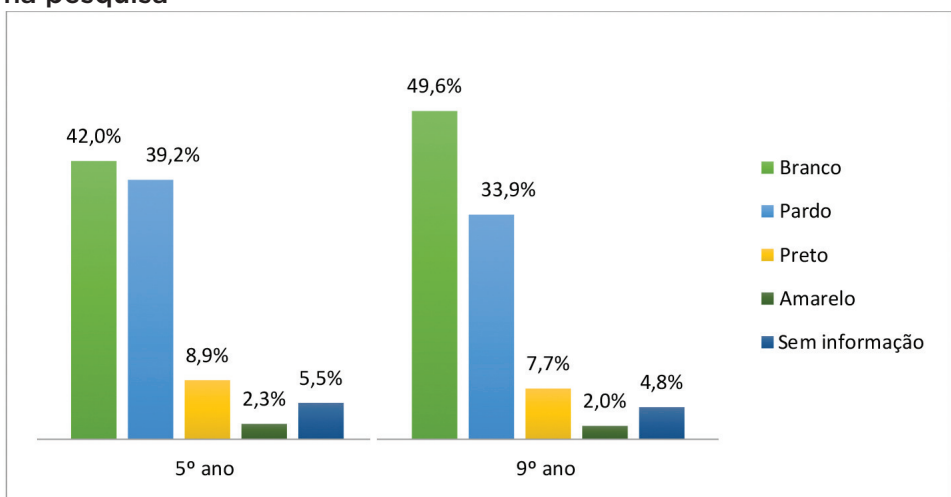

Fonte: Elaboração das autoras a partir de dados do Inep, Prova Brasil, 2013.

A Tabela 2 apresenta dados de escolaridade dos professores de $5^{\circ}$ e $9^{\circ}$ anos do ensino fundamental.

TABELA 2 - Distribuição dos professores por nível de escolaridade, para as duas séries participantes da Prova Brasil/Aneb 2013 consideradas na pesquisa

\begin{tabular}{l|c|c}
\hline $\begin{array}{l}\text { QUAL É O MAIS ALTO NÍVEL DE } \\
\text { ESCOLARIDADE QUE VOCÉ CONCLUIU? }\end{array}$ & $\mathbf{5}^{\circ}$ ANO & 9 ANO \\
\hline Menos que o Ensino Médio & 195 & 191 \\
\hline Ensino Médio - Magistério & 9.898 & 1.601 \\
\hline Ensino Médio - Outros & 1.806 & 2.144 \\
\hline Ensino Superior - Pedagogia & 52.873 & 3.887 \\
\hline Ensino Superior - Curso Normal Superior & 8.684 & 1.892 \\
\hline Ensino Superior - Licenciatura Matemática & 3.291 & 42.049 \\
\hline Ensino Superior - Licenciatura em Letras & 8.651 & 47.506 \\
\hline Ensino Superior - Outras licenciaturas & 11.007 & 8.715 \\
\hline Ensino Superior - Outras áreas & 3.684 & 3.253 \\
\hline Sem informação & 7.189 & 7.534 \\
\hline Total & 107.278 & 118.772 \\
\hline
\end{tabular}

Fonte: Inep, Prova Brasil/Aneb, 2013.

A Lei de Diretrizes e Bases da Educação Nacional (LDB) estabelece, no artigo 62, que

[...] a formação de docentes para atuar na educação básica

far-se-á em nível superior, em curso de licenciatura, de gra-

duação plena, em universidades e institutos superiores de 
No caso da docência na educação infantil e séries iniciais do ensino fundamental, a formação de nível superior exigida é o curso de Pedagogia, e, para os professores das séries finais, a formação em cursos de licenciatura específicos das disciplinas de atuação.

Os dados mostram que $66,6 \%$ dos professores que atuam no $5^{\circ}$ ano possuem a formação recomendada por lei (Ensino Médio Magistério, Ensino Superior Pedagogia ou Curso Normal Superior), sendo que 33,4\% dos docentes têm outras formações e, portanto, não atendem ao que preconiza a legislação. No caso do $9^{\circ}$ ano, 40,0\% dos professores possuem licenciatura em Letras e 35,4\%, em Matemática, sendo que 18,3\% têm formação que não atende à legislação vigente para atuar nessa etapa de ensino. Esses resultados apontam para a necessidade de implementação de iniciativas governamentais com oferta de modalidade de formação inicial para adequar a formação docente à atuação profissional, conforme exige a legislação.

Os gráficos 5a e 5b apresentam dados sobre tempo de obtenção do nível de escolaridade e tempo de trabalho como docente.

GRÁFICO 5A - Distribuição de frequência dos professores por tempo de obtenção do nível de escolaridade, para as duas séries participantes da Prova Brasil/Aneb 2013 consideradas na pesquisa

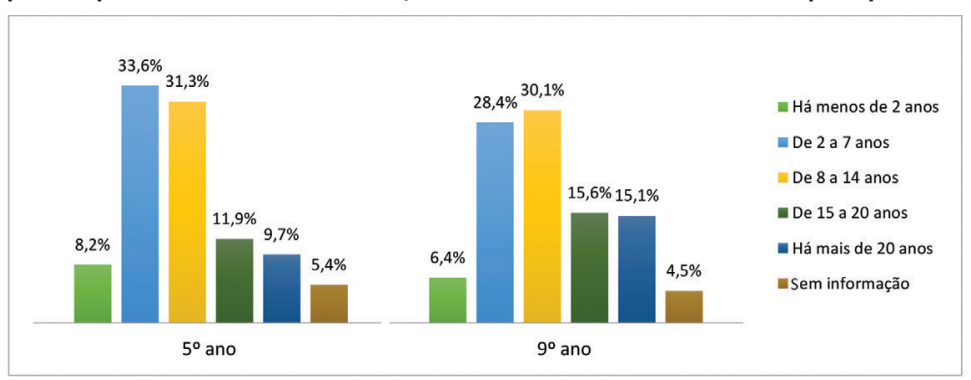


GRÁFICO 5B - Distribuição de frequência dos professores por tempo de trabalho como docente, para as duas séries participantes da Prova Brasil/Aneb 2013 consideradas na pesquisa

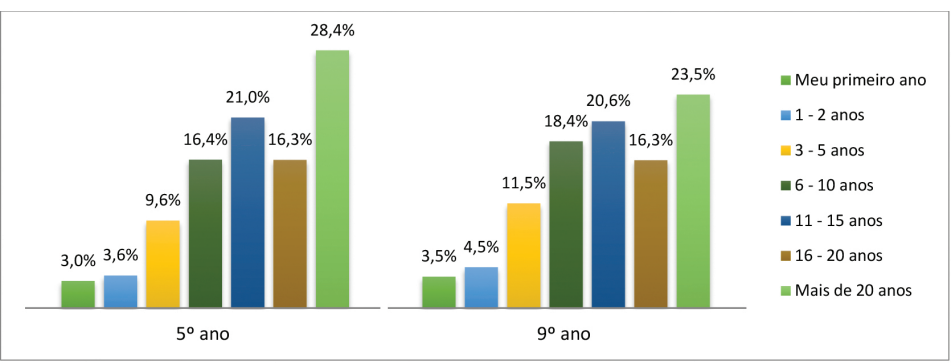

Fonte dos gráficos 5a e 5b: Elaboração das autoras a partir de dados do Inep, Prova Brasil, 2013.

Os dados mostram que $73,1 \%$ dos docentes do $5^{\circ}$ ano e $64,8 \%$ dos do $9^{\circ}$ ano concluíram o nível de escolaridade que possuem há menos de 14 anos. Com menos de 7 anos de conclusão do nível superior, temos $41,8 \%$ dos que atuam no $5^{\circ}$ ano do ensino fundamental e $34,7 \%$, no $9^{\circ}$ ano. No que se refere ao tempo de trabalho como docente, observa-se que $65,7 \%$ dos docentes do $5^{\circ}$ ano e $60,4 \%$ dos do $9^{\circ}$ ano trabalham na profissão há mais de 11 anos, o que nos leva a concluir, a partir dos dados apresentados no Gráfico 5a, que parte desses professores iniciou suas atividades laborais quando ainda cursava o ensino superior, ou mesmo antes. Importante destacar que $32,6 \%$ dos docentes do $5^{\circ}$ ano e $37,9 \%$ dos do $9^{\circ}$ ano trabalham há menos de dez anos no ensino, o que os coloca no primeiro tercil da carreira profissional.

Por outro lado, quando se observa o tempo de trabalho na série/turma em que foi aplicada a Prova, conforme o Gráfico 6, constata-se que 40,7\% atuam há menos de dois anos na mesma série/turma de $5^{\circ}$ ano e $31,4 \%$ na de $9^{\circ}$ ano. Os dados também mostram que $32,7 \%$ e $45,2 \%$ dos docentes do $5^{\circ}$ e $9^{\circ}$ anos, respectivamente, atuam na mesma turma há mais de seis anos, o que significa profissionais bastante experientes no manejo de classe e supostamente em metodologias e abordagens específicas para esses alunos. Preocupante é a situação de $22,9 \%$ dos professores de $5^{\circ}$ ano e $16,0 \%$ dos de $9^{\circ}$ ano que se encontram no primeiro ano de docência, pelo fato de o país não possuir nenhuma iniciativa que oriente ou apoie a iniciação profissional. No geral, por volta de um 
quinto dos docentes atua entre dois e três anos na mesma série/turma. Isso poderia estar associado à rotatividade dos docentes tanto no interior da escola, com mudança de série/ turma, quanto entre escolas.

GRÁFICO 6 - Distribuição de frequência dos professores por tempo de trabalho nas duas séries participantes da Prova Brasil/Aneb 2013 consideradas na pesquisa

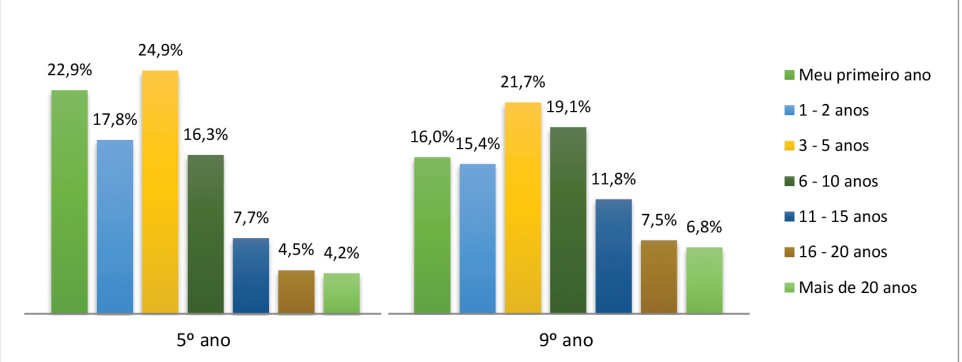

Fonte: Elaboração das autoras a partir de dados do Inep, Prova Brasil, 2013.

A formação inicial dos professores que atuam no ensino fundamental ocorre predominantemente nas instituições privadas (56,6\%) e nas instituições públicas estaduais $(21,0 \%)$, como mostra a Tabela 3.

TABELA 3 - Distribuição dos professores pelo tipo de instituição em que obteve o diploma de ensino superior, para as duas séries participantes da Prova Brasil/Aneb 2013 consideradas na pesquisa

\begin{tabular}{l|c|c}
\hline $\begin{array}{l}\text { INDIQUE EM QUE TIPO DE INSTITUIÇÃO } \\
\text { VOCÊ OBTEVE SEU DIPLOMA DE } \\
\text { ENSINO SUPERIOR }\end{array}$ & $\mathbf{5}^{\circ}$ ANO & $\mathbf{9}^{\circ}$ ANO \\
\hline Não concluí o ensino superior & 8.401 & 3.304 \\
\hline Privada & 58.848 & 69.020 \\
\hline Pública Federal & 10.842 & 15.934 \\
\hline Pública Estadual & 22.719 & 24.843 \\
\hline Pública Municipal & 1.232 & 885 \\
\hline Sem informação & 5.236 & 4.786 \\
\hline Total & 107.278 & 118.772 \\
\hline
\end{tabular}

Fonte: Inep, Prova Brasil/Aneb, 2013.

Quando analisados na perspectiva da formação continuada por meio de cursos de pós-graduação, os dados do Gráfico 7 mostram que 39,1\% e 33,4\% dos professores de 
$5^{\circ}$ e $9^{\circ}$ ano, respectivamente, não fizeram ou não completaram pós-graduação, enquanto $50,5 \%$ dos de $5^{\circ}$ ano e $54,3 \%$ dos de $9^{\circ}$ ano realizaram cursos de pós-graduação lato sensu. É insignificante o número de professores com mestrado ou doutorado atuando no ensino fundamental.

GRÁFICO 7 - Distribuição de frequência dos professores pelo tipo de curso de pós-graduação que possuem, para as duas séries participantes da Prova Brasil/Aneb 2013 consideradas na pesquisa

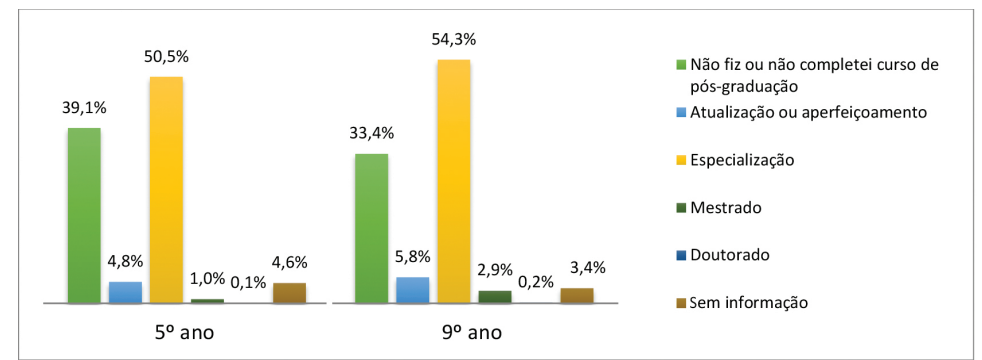

Fonte: Elaboração das autoras a partir de dados do Inep, Prova Brasil, 2013.

Quando se analisa a área temática dos cursos de pós-graduação, conforme dados da Tabela 4, constata-se que a maioria escolheu cursos na área de educação cujas ênfases não se alinham com as demandas do seu exercício profissional. No $5^{\circ}$ ano, apenas $8,5 \%$ dos docentes fizeram pós-graduação na área de alfabetização, 5,9\% na de letramento/ linguística e 2,0\% em educação matemática. No $9^{\circ}$ ano, 1,3\% dos professores fez em alfabetização, 16,2\% em linguística e/ ou letramento, e 16,9\% em educação matemática. Esse desalinhamento entre a área de atuação e a escolha pelo curso de pós-graduação sinaliza para uma procura por cursos que não estão necessariamente articulados à melhoria da prática profissional, e que pode estar associada à perspectiva de melhoria salarial, quando se sabe que os Planos de Cargos e Carreiras da grande maioria dos municípios e estados preveem acréscimos salariais para formação em nível de pós-graduação. Uma outra variável explicativa pode estar ligada à cartografia das opções de oferta desses tipos de cursos em função das localizações das instituições de ensino superior. 
TABELA 4 - Distribuição dos professores por área temática do curso de pós-graduação, para as duas séries participantes da Prova Brasil/Aneb 2013 consideradas na pesquisa

\begin{tabular}{l|c|c}
\hline $\begin{array}{l}\text { INDIQUE A ÁREA TEMÁTICA DO CURSO } \\
\text { DE PÓS-GRADUAÇÃO DE MAIS ALTA } \\
\text { TITULAÇÃO QUE VOCÊ POSSUI }\end{array}$ & $\mathbf{5 0}$ ANO & 9․ ANO \\
\hline $\begin{array}{l}\text { Não fiz ou não completei curso de pós- } \\
\text {-graduação }\end{array}$ & 42.602 & 40.985 \\
\hline Educação, enfatizando alfabetização & 9.143 & 1.539 \\
\hline $\begin{array}{l}\text { Educação, enfatizando linguística e/ou } \\
\text { letramento }\end{array}$ & 6.310 & 19.255 \\
\hline $\begin{array}{l}\text { Educação, enfatizando educação } \\
\text { matemática }\end{array}$ & 2.156 & 20.033 \\
\hline Educação - outras ênfases & 40.402 & 29.194 \\
\hline Outras áreas que não a Educação & 1.718 & 3.650 \\
\hline Sem informação & 4.947 & 4.116 \\
\hline Total & 107.278 & 118.772 \\
\hline
\end{tabular}

Fonte: Inep, Prova Brasil/Aneb, 2013.

Os Gráficos 8a e 8b apresentam dados relativos à carga horária total semanal e carga horária semanal na mesma escola.

GRÁFICO 8A - Distribuição de frequência dos professores pela carga horária total semanal, para as duas séries participantes da Prova Brasil/Aneb 2013 consideradas na pesquisa

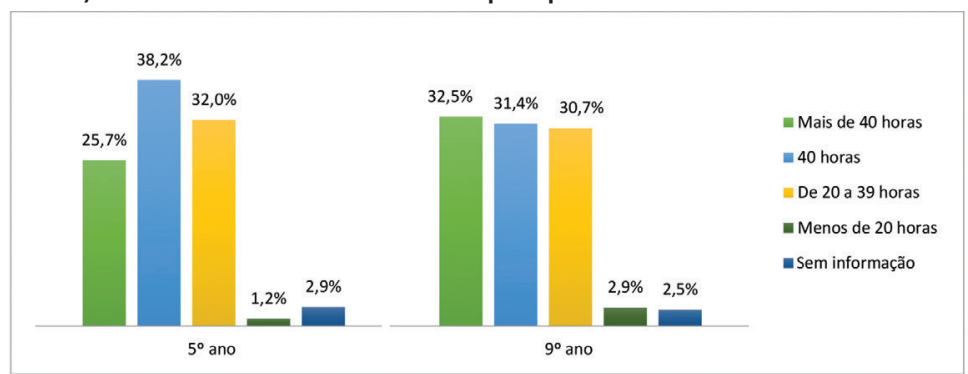

GRÁFICO 8B - Distribuição de frequência dos professores pela carga horária semanal na mesma escola, para as duas séries participantes da Prova Brasil/Aneb 2013 consideradas na pesquisa

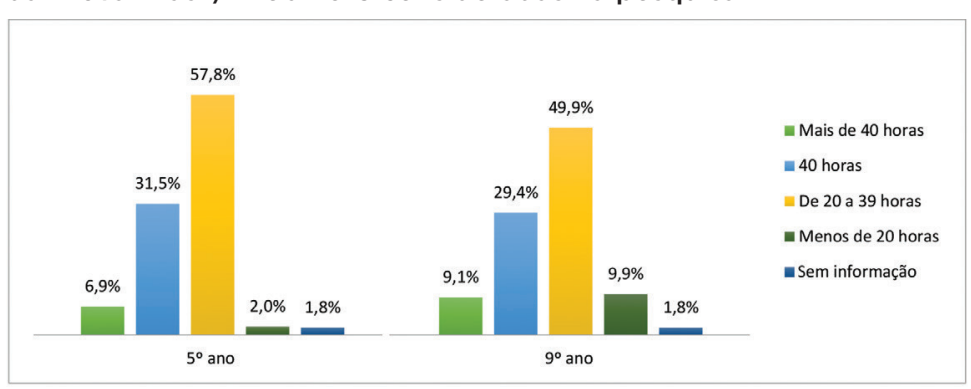

Fonte dos gráficos 8a e 8b: Elaboração das autoras a partir de dados do Inep, Prova Brasil, 2013. 
No $5^{\circ}$ ano do ensino fundamental, $38,2 \%$ dos docentes trabalham 40 horas semanais, sendo que 31,5\% trabalham na mesma escola. Já no $9^{\circ}$ ano, 31,4\% dos docentes trabalham 40 horas semanais, sendo $29,4 \%$ na mesma escola. Isso mostra que os regimes de trabalho dos professores do ensino fundamental são variados, com uma parcela de aproximadamente um terço que se enquadra no regime de 40 horas semanais, um terço em regime de mais de 40 horas e um terço com regime inferior a 40 horas. Já no que se refere à atuação na mesma escola, esses valores são superiores, com 57,8\% e $49,9 \%$ dos docentes do $5^{\circ}$ e $9^{\circ}$ anos trabalhando de 20 a 39 horas na mesma escola. Isso evidencia que uma parcela expressiva de professores desenvolve suas atividades docentes em mais de uma escola, como se verá nos dados apresentados na Tabela 5 , que mostra $32,4 \%$ dos professores do $5^{\circ}$ ano e $37,5 \%$ dos do $9^{\circ}$ ano trabalhando em duas escolas, e $5,8 \%$ dos docentes do $9^{\circ}$ ano atuando em três escolas.

TABELA 5 - Distribuição dos professores de acordo com a quantidade de escolas em que trabalham, para as duas séries participantes da Prova Brasil/Aneb 2013 consideradas na pesquisa

\begin{tabular}{l|c|c}
\hline $\begin{array}{l}\text { EM QUANTAS ESCOLAS VOCÊ } \\
\text { TRABALHA? }\end{array}$ & $\mathbf{5}^{\circ}$ ANO & $\mathbf{9}^{\circ}$ ANO \\
\hline Apenas nesta escola & 67.520 & 63.844 \\
\hline Em 2 escolas & 34.751 & 44.547 \\
\hline Em 3 escolas & 2.385 & 6.899 \\
\hline Em 4 ou mais escolas & 921 & 1.536 \\
\hline Sem informação & 1.701 & 1.946 \\
\hline Total & $\mathbf{1 0 7 . 2 7 8}$ & $\mathbf{1 1 8 . 7 7 2}$ \\
\hline Fonte: Inep, Prova Brasil/Aneb, 2013. & &
\end{tabular}

Finalmente, procurou-se analisar dados referentes à carga horária de atividades extraclasse dos docentes, apresentados no Gráfico 9. Conforme preconiza a Lei n. 11.738/2008, que institui o piso salarial nacional para os profissionais do magistério público da educação básica, no artigo $2^{\circ} \S^{\circ}$ : "na composição da jornada de trabalho, observar-se-á o limite máximo de 2/3 (dois terços) da carga horária para o desempenho das atividades de interação com os educandos”. Assim, um terço da carga horária do docente deve ser destinado às atividades extraclasse. 
Os dados mostram que $37,0 \%$ e $40,1 \%$ dos professores do $5^{\circ}$ e $9^{\circ}$ anos dedicam o que prevê a Lei para atividades extraclasse, mas 41,4\% e 36,8\% ainda não conseguem cumprir o que aponta a legislação. No outro extremo, temos $18,3 \%$ dos docentes do $5^{\circ}$ ano e $20,5 \%$ do $9^{\circ}$ ano que dedicam mais de um terço da carga horária de trabalho a atividades extraclasse.

GRÁFICO 9 - Distribuição de frequência dos professores de acordo com a carga horária de atividades extraclasse, para as duas séries participantes da Prova Brasil/Aneb 2013 consideradas na pesquisa

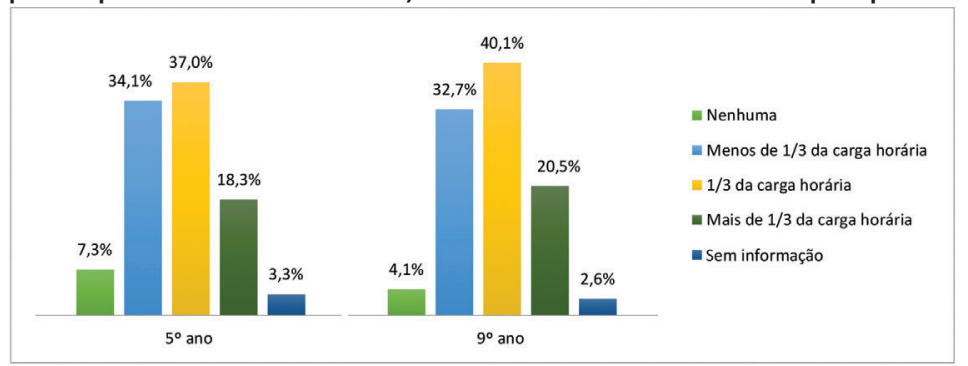

Fonte: Elaboração das autoras a partir de dados do Inep, Prova Brasil, 2013.

Considerando os dados apresentados e discutidos, é possível afirmar que predomina o sexo feminino entre os docentes tanto do $5^{\circ}$ como do $9^{\circ}$ ano, com idade média de 40 anos e tempo médio de exercício profissional de 15 anos, distribuídos entre brancos e pardos. No que se refere à formação inicial, prevalece o nível superior cursado em instituições privadas, embora essa formação nem sempre seja adequada às especificidades da legislação para cada etapa do ensino fundamental, com parte dos professores iniciando a carreira antes da conclusão do curso superior.

O cotidiano do exercício profissional é permeado pela rotatividade docente entre turmas e escolas, com parcela significativa trabalhando em mais de um estabelecimento de ensino, e cerca de um terço sem o direito aos 30\% da carga horária para atividades extraclasses, como prevê a legislação. Tais indicadores nos levam a apontar níveis de insegurança no exercício profissional associados à sobrecarga de esforços laborais.

Embora os estudos internacionais realizados no âmbito do Pisa apontem a importância da qualidade da formação 
inicial e a participação em processos de formação continuada para a preparação de um bom professor, no caso dos países latino-americanos participantes do Terce, os resultados sobre os fatores associados à melhoria da aprendizagem mostram que

Los niveles educacionales del docente, la obtención del título de profesor, la modalidad de estudio de la formación inicial, la duración de la carrera y la participación en instancias de perfeccionamiento son variables que no tuvieron una relación significativa con el logro académico. (ORGANIZACIÓN DE LAS NACIONES UNIDAS PARA LA EDUCACIÓN, LA CIENCIA Y LA CULTURA - UNESCO, 2016, p. 10)

Embora essa constatação possa estar relacionada ao fato de a maioria dos docentes possuírem características similares de formação, há que se registrar que

Existen serias deficiencias en la formacion inicial de los docentes en America Latina y el Caribe. Los futuros profesores suelen formarse en instituciones que presentan tres falencias principales: (1) excessivo enfasis en la teoria educativa, en desmedro de la practica pedagogica; (2) falta de una solida formacion disciplinaria con enfasis en como ensenar la disciplina; y (3) practicas profesionales desvinculadas del proceso de formacion, usualmente porque no tienen supervision adecuada, son demasiado cortas, o porque estan al final del programa de estudio (RAMIREZ; VITERI, 2016, p. 59 apud UNESCO, 2013; LOUZANO; MORICONI, 2014).

Os resultados da pesquisa mostram que o perfil do professor brasileiro possui elementos comuns aos que os estudos internacionais definem como importantes para a qualidade do docente; no entanto, como bem mostra a constatação da Oficina Regional de Educação para a América Latina e Caribe (Orealc) (UNESCO, 2016), o país convive com problemas de qualidade na oferta da formação inicial, além do que, pela atratividade da carreira ser baixa, quem procura o magistério situa-se nos setores mais empobrecidos 
da população (VAILLANT, 2006), possuindo baixo capital social e cultural.

O tópico a seguir analisa alguns indicadores relacionados à utilização do tempo pedagógico na visão dos professores. Para tanto, procurou-se aprofundar algumas questões presentes no Questionário do Professor da Prova Brasil/Aneb 2013.

\section{PROBLEMAS DE APRENDIZAGEM E USOS DO TEMPO PEDAGÓGICO NA VISÃO DOS PROFESSORES}

A discussão sobre a relação entre a aprendizagem dos alunos, qualidade da educação e características docentes não é recente e, como vimos nos estudos apresentados no tópico 1 deste artigo, há relativo consenso acerca da centralidade desse profissional na determinação da qualidade da educação oferecida. Entre as características apontadas pelos estudos para o sucesso da aprendizagem discente, está o elevado senso de responsabilidade profissional dos docentes em relação ao sucesso dos alunos e ofato desses sentirem-se imbuídos de uma missão moral subjacente aos esforços de educação.

No Questionário do Professor da Prova Brasil/Aneb 2013, um grupo de questões (70-82) procura identificar percepções docentes sobre problemas de aprendizagem dos alunos, e outras questões (102-104 e 106) investigam junto aos professores o aproveitamento do tempo de aula e a quantidade de conteúdo curricular trabalhado no ano letivo.

O Gráfico 10a apresenta dados acerca do tempo de aula despendido pelos docentes com a realização de tarefas administrativas, e nele podemos constatar que $66,1 \%$ dos professores do $5^{\circ}$ ano e $68,9 \%$ do $9^{\circ}$ ano afirmam gastar menos de $10 \%$ do tempo, sendo que $20,7 \%$ dos docentes do $5^{\circ}$ ano e $21,4 \%$ dos de $9^{\circ}$ ano gastam de $10 \%$ a menos de $20 \%$. 
GRÁFICO 10A - Distribuição de frequência dos professores segundo o tempo gasto na realização de tarefas administrativas, para as duas séries participantes da Prova Brasil/Aneb 2013 consideradas na pesquisa

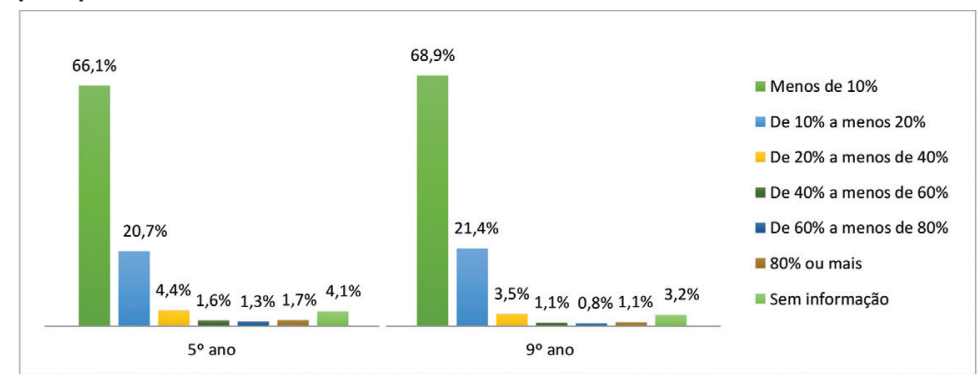

GRÁFICO 10B - Distribuição de frequência dos professores segundo o tempo gasto mantendo a ordem/disciplina na sala de aula, para as duas séries participantes da Prova Brasil/Aneb 2013 consideradas na pesquisa

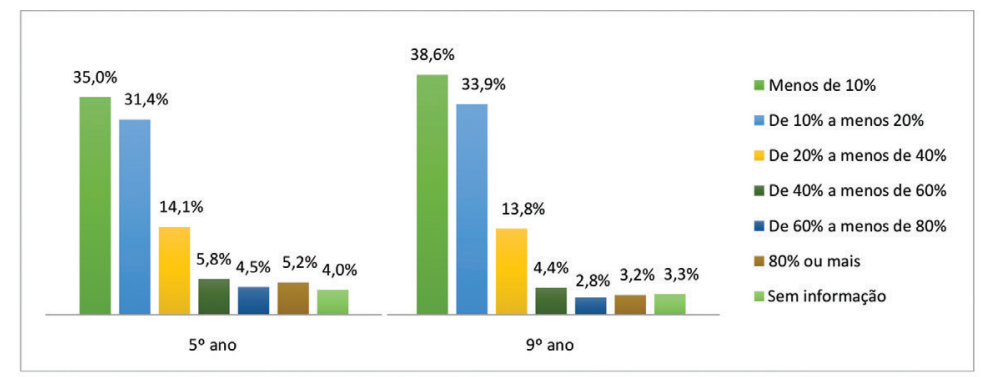

Fonte dos gráficos 10a e 10b: Elaboração das autoras a partir de dados do Inep, Prova Brasil, 2013.

O Gráfico 10b, por sua vez, apresenta informações sobre o tempo de aula que o docente gasta mantendo a ordem/ disciplina na sala e mostra que $29,5 \%$ e $24,4 \%$ dos professores de $5^{\circ}$ e $9^{\circ}$ anos, respectivamente, despendem mais de $20 \%$ do tempo de aula nessa atividade.

Observando aqueles docentes que afirmam gastar de $10 \%$ a menos de $20 \%$ nos dois anos $\left(31,4 \%\right.$ no $5^{\circ}$ ano e $33,9 \%$ no $9^{\circ}$ ano), constata-se que um terço dos professores despendem mais de $10 \%$ do tempo de aula para manter a ordem/ disciplina. Os dados dos dois gráficos anteriores revelam que parcela expressiva dos docentes do $5^{\circ}$ e $9^{\circ}$ anos gasta mais de $20 \%$ do tempo de aula com atividades burocráticas e de manutenção da ordem na sala de aula. Em 2014, foram publicados resultados relativos à Pesquisa Internacional sobre Ensino e Aprendizagem (Talis), da qual o país participou, e os dados mostram que "entre os países pesquisados, o Brasil 
é o local onde os professores dedicam o menor tempo médio em sala de aula com ensino e aprendizagem" (BRASIL, 2014, p. 18), com uma média de $32,0 \%$ do tempo de aula destinados a tarefas administrativas e a manter a ordem.

No caso dos dados obtidos para os professores de $5^{\circ} \mathrm{e}$ $9^{\circ}$ anos, a considerar as 800 horas mínimas de aula por ano, como prevê a LDB para o ensino fundamental, seriam 160 horas de prejuízo ao processo ensino-aprendizagem, levando, certamente, a comprometimento curricular. Segundo a publicação da Unesco/Orealc (ROJAS; GASPAR, 2006, p. 113) sobre bases da liderança em educação, o tempo pedagógico é fator relevante associado à aprendizagem escolar e seu mau uso pode levar à baixa eficiência da escola:

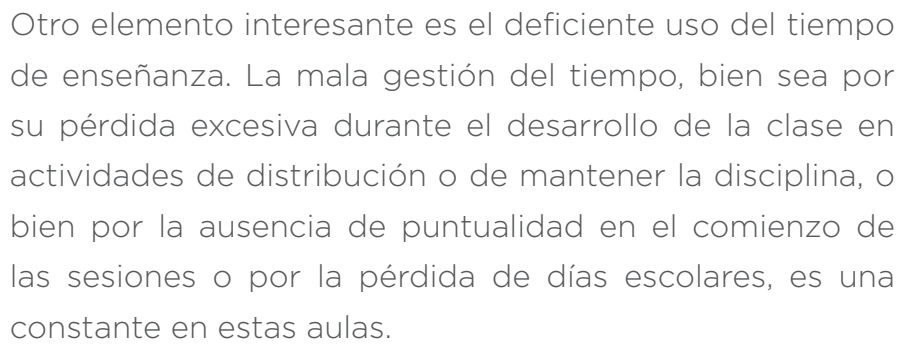

O Gráfico 11 apresenta dados sobre o tempo de sala de aula destinado à realização de atividades de ensino e aprendizagem e mostra que apenas $43,4 \%$ e $38,2 \%$ dos docentes do $5^{\circ}$ e $9^{\circ}$ anos dedicam $80 \%$ ou mais de tempo à realização de atividades de ensino e aprendizagem. Ainda se registra que 22,1\% dos professores de $5^{\circ}$ e $25,3 \%$ dos de $9^{\circ}$ ano dedicam menos de $60 \%$ do tempo de aula ao cumprimento do currículo. 
GRÁFICO 11 - Distribuição de frequência dos professores de acordo com o tempo empregado na realização de atividades de ensino e aprendizado, para as duas séries participantes da Prova Brasil/Aneb 2013 consideradas na pesquisa

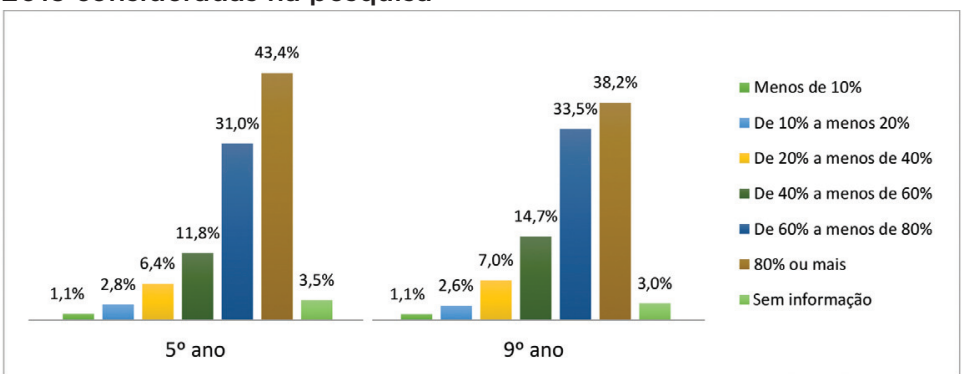

Fonte: Elaboração das autoras a partir de dados do Inep, Prova Brasil, 2013.

Por isso, quando indagados sobre a quantidade de conteúdo previsto para o ano letivo que o professor conseguiu cumprir, conforme o Gráfico 12 mostra, apenas 50,0\% dos docentes de $5^{\circ}$ ano e $43,0 \%$ dos de $9^{\circ}$ ano conseguem atingir $80 \%$ ou mais do conteúdo, sendo que $36,3 \%$ e $40,9 \%$ dos respectivos professores situam-se na faixa de $60 \%$ a menos de $80 \%$.

GRÁFICO 12 - Distribuição de frequência dos professores de acordo com a parcela do conteúdo previsto que foi efetivamente desenvolvida no ano, para as duas séries participantes da Prova Brasil/Aneb 2013 consideradas na pesquisa

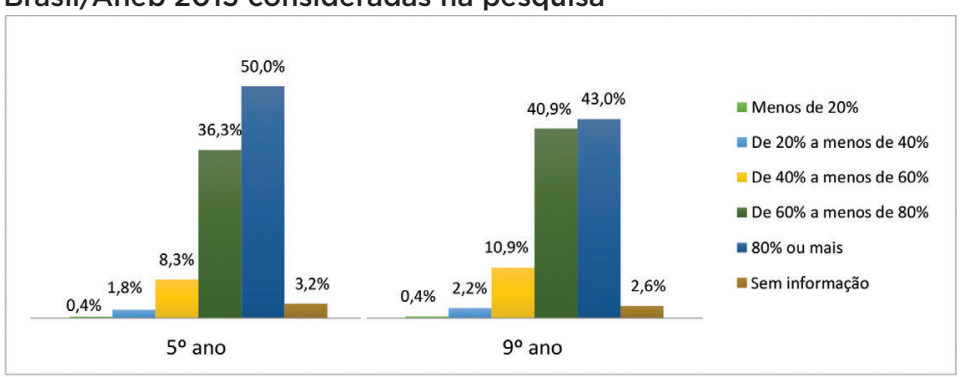

Fonte: Elaboração das autoras a partir de dados do Inep, Prova Brasil, 2013.

A considerar que o país ainda não possui uma base curricular nacional e que o conteúdo a que se referem os professores deve estar relacionado à proposta pedagógica da escola, que se expressa substancialmente pelo livro didático adotado, e que esse processo se repete ano a ano, pode-se inferir que os alunos acumulam expressivos déficits de 
conhecimento ao longo de sua escolarização no ensino fundamental, sendo a situação mais grave no $9^{\circ}$ ano.

Finalmente, foi investigado como os docentes percebem os possíveis problemas de aprendizagem dos alunos, das série(s) ou ano(s) avaliado(s), por meio de um bloco de 13 questões, como podemos observar nos gráficos 13a e 13b.

GRÁFICO 13A - Percepção dos docentes participantes da Prova Brasil/Aneb 2013 acerca da existência ou não de possíveis problemas de aprendizado dos alunos do $5^{\circ}$ ano

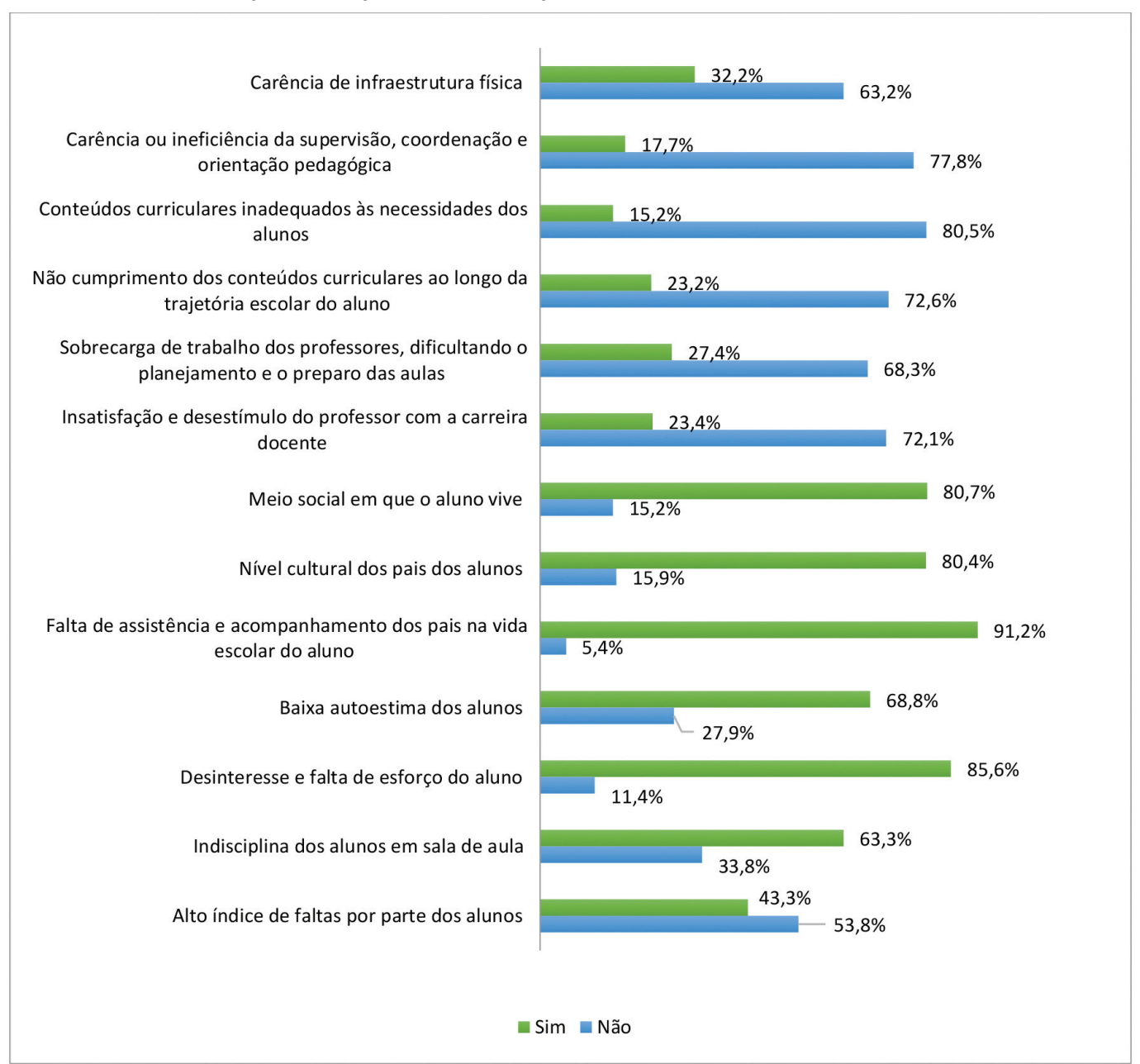

Fonte: Elaboração das autoras a partir de dados do Inep, Prova Brasil, 2013. 
GRÁFICO 13B - Percepção dos docentes participantes da Prova Brasil/Aneb 2013 acerca da existência ou não de possíveis problemas de aprendizado dos alunos do $9^{\circ}$ ano

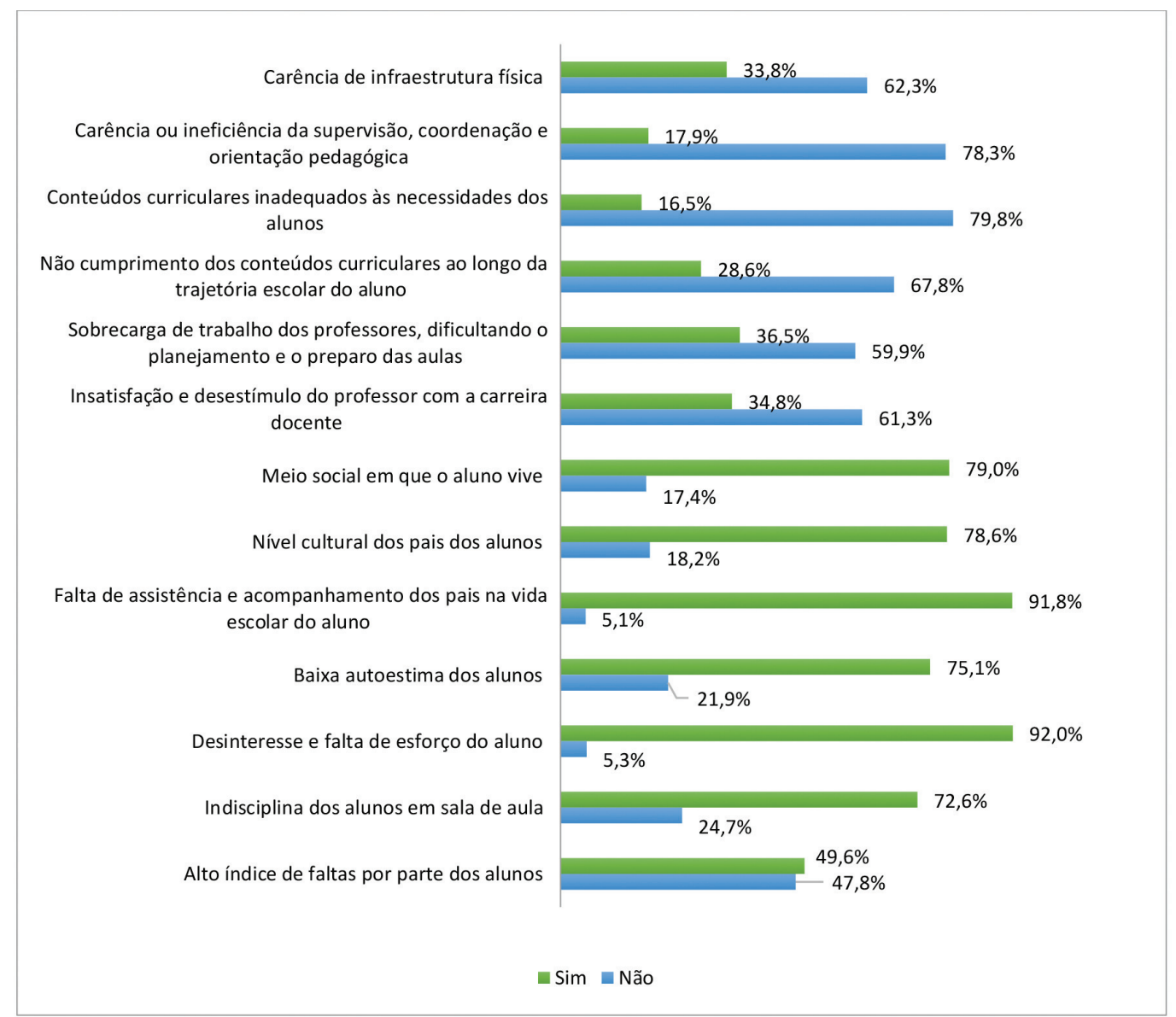

Fonte: Elaboração das autoras a partir de dados do Inep, Prova Brasil, 2013.

Para mais de $60 \%$ dos docentes de $5^{\circ}$ e $9^{\circ}$ anos, a carência de infraestrutura física na escola não representa problema para a aprendizagem dos alunos. A carência ou ineficiência de serviços de apoio pedagógico (supervisão, coordenação e orientação) também não está associada a problemas de aprendizagem dos alunos para $77,8 \%$ dos professores de $5^{\circ}$ ano e $78,3 \%$ dos de $9^{\circ}$ ano.

Na dimensão curricular, a inadequação dos conteúdos às necessidades dos alunos e o não cumprimento desses ao longo da trajetória escolar dos estudantes tem pouco impacto sobre possíveis problemas de aprendizagem. Apenas $15,2 \%$ e $16,5 \%$ dos professores de $5^{\circ}$ e $9^{\circ}$ anos, respectivamente, consideram que a inadequação do currículo tem relação com 
problemas de aprendizagem, enquanto $23,2 \%$ e $28,6 \%$ dos docentes dos mesmos anos avaliam que o não cumprimento do currículo ao longo da trajetória escolar produz efeitos nocivos na aprendizagem dos alunos.

Quando indagados sobre a associação de problemas de aprendizagem dos alunos com carga de trabalho, 68,3\% e $59,9 \%$ dos professores de $5^{\circ}$ e $9^{\circ}$ anos não veem relação, mas $23,4 \%$ e $34,8 \%$ desses mesmos docentes consideram o desestímulo do professor com a carreira uma variável relacionada a problemas de aprendizagem discente.

Chama a atenção o fato de os professores dos $5^{\circ}$ e $9^{\circ}$ anos atribuírem os problemas de aprendizagem dos alunos a fatores externos à escola, com maior destaque para o meio social em que o aluno vive (80,7\% e 79,0\%), o nível cultural dos pais dos alunos $(80,4 \%$ e 78,65$)$, a falta de assistência e acompanhamento dos pais na vida escolar do aluno (91,2\% e 91,8\%), a baixa autoestima dos alunos (68,8\% e 75,1\%), o desinteresse e falta de esforço do aluno (85,6\% e $92,0 \%$ ) e a indisciplina dos alunos em sala de aula (63,3\% e 72,6\%). Curiosamente, o alto índice de faltas por parte dos alunos não é visto como causador de possíveis problemas de aprendizagem para $53,8 \%$ dos professores de $5^{\circ}$ ano e $47,8 \%$ do $9^{\circ}$ ano.

Aspectos relacionados à gestão da escola, ao currículo, à carência de infraestrutura e às condições laborais dos próprios docentes - portanto, variáveis internas à escola - apresentam contribuições significativamente inferiores para os possíveis problemas de aprendizagem dos alunos. Ou seja, persistem, na visão dos docentes, ideias acerca da impossibilidade de a escola fazer a diferença na vida do aluno, assim como ausência de percepção em relação aos resultados alcançados, afinal, em razão das condições externas, o insucesso é o "destino" desses alunos.

Numa publicação da Unesco/Orealc (ROJAS; GASPAR, 2006, p. 73) sobre bases da liderança em educação, entre os fatores associados à aprendizagem escolar, a postura dos docentes é determinante, como podemos observar:

Los/las docentes con altas expectativas, esto es, que confían en que sus alumnos y alumnas están habilitados para aprender - cualquiera sea su situación sociofamiliar -, tienen mucho mejor desempeño y logran más resultados 
que aquellos docentes que se obstinan en negar la existência de habilidades de aprendizaje en sus alumnos, en especial, por la situación sociofamiliar en la que viven.

Um outro estudo, realizado por Hernández-Castilla, Murillo e Martínez-Garrido, discute aspectos relacionados a fatores de ineficácia escolar è̀s expectativas dos professores sobre as capacidades dos alunos, que são determinantes para o sucesso na aprendizagem, como é possível observar, quando eles afirmam que:

En el discurso de los profesores, la tendencia principal que aparece es la de una percepción y visualización de los niños y sus familias en términos de sujetos carentes de condiciones básicas para iniciar procesos de aprendizajes relevantes. Muchos de los docentes subrayan que los niños muestran muy pocas habilidades cognitivas y sociales. De acuerdo con su opinión, la mayoría de los niños y niñas son lentos, carecen de concentración, de motivación y no son perseverantes. (HERNÁNDEZ-CASTILLA; MURILLO; MARTÍNEZ-GARRIDO, 2013, p. 111)

Aspectos relativos à baixa autoestima dos alunos, desinteresse e falta de esforço, além de indisciplina em sala de aula, estariam relacionados ao que o autor enumera como fatores responsáveis pelo insucesso escolar.

Assim, as expectativas docentes funcionam como fatores determinantes que marcam a instituição escolar e isentam-nos de qualquer resultado em relação ao sucesso escolar; afinal, suas percepções estão ancoradas no fato de que os fatores externos às escolas, de que os alunos são portadores, são determinantes nas suas vidas escolares, e sobre isso não há muito o que fazer. A pesquisa realizada por Hernándes-Castilla, Murillo e Martínez-Garrido, (2013, p. 111-112) mostrou que:

En conjunto, entre los maestros al no disponer de altas expectativas en cuanto al futuro de sus alumnos y lo suelen identificar como principales responsables de los resultados académicos alcanzados y de las insuficiencias existentes.

$[\ldots]$

Los profesores expresan que es muy poco lo que se puede hacer por estos niños, porque las condiciones de 
Uma pesquisa realizada por Tacca $(1999$, p. 86$)$ relaciona o fracasso escolar ao "sistema de crenças" do professor, que "o fortalecia ou o desanimava no enfrentamento da sua sala de aula", construído a partir de seu contexto social e cultural. Os resultados da sua pesquisa mostram que "os professores se dispunham a explicar fracasso e sucesso a partir dos mesmos fatores e condições" (TACCA, 1999, p. 92). Mas, enquanto o fracasso era explicado colocando em primeiro plano referências ao aluno e sua família como fatores interligados, passando por considerações de classe social a que pertenciam, o sucesso trazia o professor para a posição de protagonista, envidando esforço, interesse, afetividade e acompanhamento do aluno, ficando o empenho da família e do aluno em segundo plano.

Os dados obtidos nesta pesquisa parecem apontar que a dificuldade na melhoria dos resultados de desempenho dos alunos brasileiros nas avaliações de larga escala pode estar relacionada com esse "sistema de crenças" de parcela expressiva dos docentes, que a priori, e muitas vezes de forma subjetiva, já nutrem baixa expectativa de aprendizagem dos alunos. Alterar tal expectativa é não apenas fator importante para reverter a situação existente, mas também elemento a ser considerado em políticas de formação docente.

\section{CONSIDERAÇÕES FINAIS}

No que diz respeito ao perfil profissional dos docentes que atuam nas disciplinas de Língua Portuguesa e Matemática nos $5^{\circ}$ e $9^{\circ}$ anos das escolas públicas brasileiras, os dados permitem afirmar que esses professores: já possuem formação superior, embora nem sempre alinhada com seu lócus de atuação profissional; têm procurado se especializar, no entanto, com opções de formação que, na maioria das vezes, não condizem com sua área de atuação; e grande parte conseguiu, a partir de 2008, assegurar um terço de sua carga horária de trabalho a atividades extraclasse. Por outro lado, 
observam-se as atividades laborais desses profissionais permeadas por sobressaltos, como alta rotatividade entre turmas e escolas - o que fragiliza suas práticas pedagógicas -, atuação em mais de um estabelecimento de ensino, representando grande esforço cotidiano, o que compromete também o preparo de aulas e a participação em ações de formação continuada.

No entanto, os aspectos que mais chamaram a atenção no estudo dizem respeito às percepções docentes sobre os problemas de aprendizagem dos alunos, na medida em que parcela bastante expressiva atribui tais dificuldades a fatores externos à escola, apontando para um processo de isenção profissional da função última e primordial da escola, que é zelar pelo ensino e aprendizagem.

Como apontam estudos da Unesco/Orealc (ROJAS; GASPAR, 2006) e recente pesquisa de Hernández-Castilla, Murillo e Martínez-Garrido (2014), uma visão pessimista sobre o aluno está enraizada na postura docente e repercute na sua prática, conduzindo à ineficácia escolar. A melhoria dos resultados de aprendizagem dos alunos brasileiros está, em parte, vinculada a uma nova postura dos professores diante do processo de ensino e aprendizagem.

Ao cotejar os resultados obtidos, a partir da análise dos dados, com as principais características docentes identificadas nos estudos internacionais e nacionais, pode-se inferir que, embora se tenha avançado na busca de melhorias na educação, investindo esforços em formação inicial e continuada de professores, e nas condições de trabalho com a criação da Lei do Piso (BRASIL, 2008), os docentes brasileiros apresentam percepções sobre os alunos que os levam a considerar as variáveis extraescolares mais relevantes e de maior impacto na vida escolar dos alunos que as variáveis intraescolares, que estariam no âmbito da gestão escolar e ação docente, especialmente aquelas que dizem respeito ao processo de ensino e aprendizagem. Prevalece a visão de que as variáveis extraescolares definem o "destino" da trajetória escolar do aluno e de que sobre isso não há muito o que fazer. 


\section{REFERÊNCIAS}

ARRETCHE, Marta. Federalismo e políticas sociais no Brasil: problemas de coordenação e autonomia. In: SARAVIA, Enrique; FERRAREZI, Elisabete (Org.). Políticas públicas: coletânea. Brasília, DF: Enap, 2006. p. 91-110. v. 2.

BRASIL. Ministério da Educação. Instituto Nacional de Estudos e Pesquisas Educacionais Anísio Teixeira. Microdados Saeb (Aneb/Prova Brasil) 2013: Questionário do Professor. Brasília, DF, 2013. Disponível em: <http://portal. inep.gov.br/basica-levantamentos-acessar.> Acesso em: 14 fev. 2016.

BRASIL. Ministério da Educação. Instituto Nacional de Estudos e Pesquisas Educacionais Anísio Teixeira. Pesquisa internacional sobre ensino e aprendizagem (Talis): relatório nacional. Brasília, DF, 2014. Disponível em: < http:// download.inep.gov.br/acoes_internacionais/pesquisa_talis/2013/talis2013_ relatorio_brasil.pdf $>$. Acesso em: 5 maio 2016.

BRASIL. Ministério da Educação. Instituto Nacional de Estudos e Pesquisas Educacionais Anísio Teixeira. Sinopse estatística da educação básica 2014. Brasília, DF, 2016. Disponível em: <http://portal.inep.gov.br/ basica-censoescolar-sinopse-sinopse>. Acesso em: 14 fev. 2016.

BRASIL. Ministério da Educação; FUNDO DAS NAÇÕES UNIDAS PARA A INFÂNCIA. Aprova Brasil - o direito de aprender: boas práticas em escolas públicas avaliadas para Prova Brasil. Brasília, DF: Inep, 2007. Disponível em: <http://www.inep.gov.br> Acesso em: 31 jan. 2008.

BRASIL. Ministério da Educação. Instituto Nacional de Estudos e Pesquisas Educacionais; FUNDO DAS NAÇÕES UNIDAS PARA A INFÂNCIA; UNIÃO DOS DIRIGENTES MUNICIPAIS DE EDUCAÇÃO. Redes de aprendizagem: boas práticas de municípios que garantem o direito de aprender. Brasília, DF: Unicef; MEC/Inep; Undime, [ca. 2009].

BRASIL. Presidência da República. Casa Civil. Subchefia para Assuntos Jurídicos. Lei n. 11.738, de 16 de julho de 2008. Regulamenta a alínea "e" do inciso III do caput do art. 60 do Ato das Disposições Constitucionais Transitórias, para instituir o piso salarial profissional nacional para os profissionais do magistério público da educação básica. Brasília, DF, 2008. Disponível em: <http:/|www.planalto.gov.br/ ccivil_03/_ato2007-2010/2008/ lei/111738.htm>. Acesso em: 14 fev. 2016.

BRASIL. Presidência da República. Lei n. 12.796, de 4 de abril de 2013. Altera a Lei n. 9.394, de 20 de dezembro de 1996, que estabelece as diretrizes e bases da educação nacional, para dispor sobre a formação dos profissionais da educação e dar outras providências. Brasília, DF: Casa Civil, 2013.

HERNÁNDEZ-CASTILLA, Reyes; MURILLO, F. Javier; MARTÍNEZ-GARRIDO, Cynthia. Factores de ineficacia escolar. REICE. Revista Iberoamericana sobre Calidad, Eficacia y Cambio en Educación, v. 12, n. 1, p. 103-118, 2014.

LOUZANO, Paula; MORICONI, Gabriela. Vision de la docencia y caracteristicas de los sistemas de formacion docente. In: ORGANIZACIÓN DE LAS NACIONES UNIDAS PARA LA EDUCACIÓN, LA CIENCIA Y LA CULTURA. Temas criticos para formular nuevas politicas docentes em America Latina y el Caribe: el debate actual. Santiago: Unesco/Orealc, 2014. p. 10-53. 
McKINSEY \& COMPANY. How the world's best-performing school systems come out on top (Como os sistemas escolares de melhor desempenho do mundo chegaram ao topo). 2007. Disponível em: <http://mckinseyonsociety.com/ how-the-worlds-best-performing-schools-come-out-on-top/>. Acesso em: $13 \mathrm{fev} .2016$.

McKINSEY \& COMPANY. Educação: como um sistema escolar de baixo desempenho pode evoluir para tornar-se bom? E como um sistema de bom desempenho pode atingir o nível de excelência? 2010. Disponível em: $<$ http://mckinseyonsociety.com/how-the-worlds-most-improved-schoolsystems-keep-getting-better/> . Acesso em: 23 jan. 2013.

ORGANIZACIÓN DE LAS NACIONES UNIDAS PARA LA EDUCACIÓN, LA CIENCIA Y LA CULTURA. Antecedentes $y$ criterios para la elaboracion de politicas docentes em America Latina y el Caribe. Santiago: Unesco/Orealc, 2013. Disponível em: <http://politicasdocentesalc.com/images/stories/ politicasdocentesespanol27082013.pdf>. Acesso em: 3 abril 2017.

ORGANIZACIÓN DE LAS NACIONES UNIDAS PARA LA EDUCACIÓN, LA CIENCIA Y LA CULTURA. Factores asociados. Informe de resultados del Tercer Estudio Regional Comparativo y Explicativo (TERCE). Informe de resultados, Julio 2015. Santiago: Unesco/Orealc, 2016. (Cuadernillo n. 3). Disponível em: $<$ http://unesdoc.unesco.org/images/0024/002435/243533s.pdf>. Acesso em: 3 abril 2017.

PARANDEKAR, Suhas D.; OLIVEIRA, Isabel de Assis Ribeiro de; AMORIM, Érica (Org.). Desempenho dos alunos na Prova Brasil: diversos caminhos para o sucesso educacional nas redes municipais de ensino Brasília, DF: Inep, 2008. $215 \mathrm{p}$.

PEARSON. DEVELOPED BY THE ECONOMIST INTELLIGENCE UNIT. The education curve: lessons in country performance in education. 2012 Report. New York: Pearson. Developed by the Economist Intelligence Unit. Disponível em: < http://thelearningcurve.pearson.com/>. Acesso em: 28 fev. 2012.

RAMIREZ, Maria Jose; VITERI, Adriana. Los docentes de tercer y sexto grado de America Latina y el Caribe: caracteristicas, percepciones y relacion con el aprendizaje de los estudiantes. Santiago: Unesco/Orealc, 2016. Disponível em: <http://www.unesco.org/new/fileadmin/MULTIMEDIA/FIELD/Santiago/ pdf/docentes-tercer-sexto-grado-LAC.pdf>. Acesso em: 27 ago. 2016.

ROJAS, Alfredo; GASPAR, Fernando (Org.). Bases del liderazgo en educación. Santiago: Unesco/Orealc, ago. 2006.

TACCA, Maria Carmen V. R. Professores, suas crenças e a possibilidade de sucesso de seus alunos. Linhas Críticas, Brasília, DF, v. 5, n. 9, p. 85-102, jul./dez. 1999. Disponível em: <http://periodicos.unb.br/index.php/ linhascriticas/article/view/6714>. Acesso em: 27 ago. 2016.

VAILLANT, Denise. Atraer y retener buenos profesionales em la profesión docente: políticas em Latinoamerica. Revista Educación, Madrid, n. 340, p. 117-140, mayo/ago. 2006. 
WERLE, Flavia Correa Obino. Práticas de gestão e feminização do magistério. Cadernos de Pesquisa, São Paulo, v. 35, n. 126, p. 609-634, set./dez. 2005. Disponível em: <http://www.scielo.br/ pdf/cp/v35n126/a05n126.pdf> . Acesso em: 21 abr. 2014

\section{ELOISA MAIA VIDAL}

Professora associada da Universidade Estadual do Ceará (Uece),

Fortaleza, Ceará, Brasil

eloisamvidal@yahoo.com.br

SOFIA LERCHE VIEIRA

Professora titular da Universidade Estadual do Ceará (Uece), Fortaleza, Ceará, Brasil

sofialerche@gmail.com 